NASZA DERMATOLOGIA Online OUR DERMATOLOGY Online

Source of Support:

Nil

Competing Interests:

None

\section{EVALUATION OF THERAPEUTIC RESPONSE OF METHOTREXATE AND CALCIPOTRIOL COMBINATION COMPARED WITH METHOTREXATE ALONE IN PLAQUE PSORIASIS}

\author{
Vasanthada Deepthi ${ }^{1}$, PM Vasanth Kumar' ${ }^{2}$, \\ Pasagadagula Krishna Rao ${ }^{3}$, Tatapudi Ramesh ${ }^{4}$, Malothu Ramesh ${ }^{4}$ \\ ${ }^{1} U C E V-J N T U K$, Vizianagaram Campus, A.P, India \\ ${ }^{2}$ Department of Pharmacy, UCEV-JNTUK, Vizianagaram Campus, A.P, India \\ ${ }^{3}$ Department of Dermatology Venerology and Leprosy, Andhra Medical College, \\ Visakhapatnam, A.P, India \\ ${ }^{4}$ Department of Biotechnology, UCEV-JNTUK, Vizianagaram campus, A.P, India
}

Corresponding author: Dr. PM Vasanth Kumar

vasanthpharma@gmail.com

\begin{abstract}
Introduction: Psoriasis is a common chronic, non-contagious, immune mediated disease. Plaque psoriasis is characterized by thick, white, silvery or red patches on the skin. Plaque psoriasis mainly affects scalp, and palms of hands and soles of feet. T-cells are a type of immune system cells which protect the body from foreign substances. But during psoriasis T-cells activated at a great rate than normal, in turn release of cytokines increases as a result skin cells growing too quickly, moving to the surface to the skin and appear on the skin as dead cells.

Materials and Methods: Plaque psoriasis is common form of psoriasis, which mainly affects palms of hands and soles of feet and scalp. Out of 76 patients with plaque psoriasis we selected 50 patients based on PASI scores. Within the 50 patients, 32 patients with Palmoplantar psoriasis and 18 patients with scalp psoriasis. All 50 patients were subjected to randomized control trail, so each type of psoriasis is divided into two groups i.e. A and B. All A group patients were treated with MTX, whereas all B group patients were treated with combination of MTX and Calcipotriol. All necessary investigations like complete blood count, liver enzyme,creatinine, urea, alkaline phosphate, PASI were measured at $0,2,46,8$ weeks interval.

Results: We observed that, a significant reduction in PASI is observed with combination of MTX and Calcipotriol as compared to Methotrexate alone.

Conclusion: From the above study we concluded that, combination of MTX and Calcipotriolis more effective than MTX alone in plaque psoriasis.
\end{abstract}

Key words: Plaque psoriasis; Methotrexate; Calcipotriol; PASI

\section{Introduction}

Psoriasis is a common chronic, non-contagious, immune mediated disease. Psoriasis is mainly five types; they are plaque, guttate, inverse, pustular, erythrodermic. The most common form, plaque psoriasis, is characterized by thick, white, silvery or red patches on the skin. Plaque psoriasis mainly affects the scalp, and the palms of the hands and the soles of the feet. T-cells are a type of immune system cells which protect the body from foreign substances. But during psoriasis T-cells activates at a great rate than normal, in turn releases cytokines, which increases rapidly $[1,2]$. These cytokines stimulate skin cells to reproduce and mature at a faster rate, as a result skin cells growing too quickly, moving to the surface of the skin and appear on the skin as dead cells.

Methotrexate is an anti folate, anti-metabolite drug, used in the treatment of auto immune diseases Methotrexate inhibits enzyme Dihydrofolatereductaseenzyme that involves in the production of tetrahydrofolate from dihydrofolate. As a result folic acid synthesis is inhibited, it is essential for DNA, RNA, and Thymidine synthesis. DNA, RNA, Thymidine are required for new cell growth and multiplication [3-5]. Methotrexate also inhibits T-cells activation. 
Calcipotriol is a vitamin D analogue, upon topical administration which binds with vitamin D receptor (VDR). Vitamin D receptor is found on the cells of many different tissues of thyroid, Bone, kidney and T-cells of immune system. T-cells play a major role in psoriasis; calcipotriol binds with vitamin D receptors of T-cells, and modulate T- cells cell growth and differentiation. Psoriasis is a complex disease, so combination therapy is beneficial that minimize risks [6-9]. Calcipotriol have antiinflammatory, anti-proliferative, immunomodulatory properties. By using topical calcipotriol along with methotrexate reduces toxicities that associates with use of methotrexate as monotherapy, as well as calcipotriol also increases safety and efficacy of Methotrexate.

\section{Material and Methods}

I. Patient's information

In this study, 76 patients with plaque psoriasis attended to the skin O.P. department K.G.H. Visakhapatnam. We selected 50 patients based on the psoriasis area severity index (PASI) and all necessary laboratory investigations were performed for present study. Out of 50 patients, 33 (66\%) were males and 17 (34\%) were females, and patients age ranged between 20 to 65 years (Tabl. I).

Among the 50 patients, 32 patients with Palmoplantar psoriasis, 18 patients with scalp psoriasis. The extent of psoriasis was measured by using PASI scores (Tabl. II).

\section{Grouping of patients}

Grouping of patients is very essential, where each type of psoriasis is divided into two groups, based on Randomized control trail (RCT). By using Randomized control we can achieve equal groups and minimize errors. In this present study we selected Block type of randomized control trail (Tabl. III).

\begin{tabular}{|c|c|c|}
\hline \multirow{2}{*}{ Sex } & Male & $33(66 \%)$ \\
\cline { 2 - 3 } & Female & $17(34 \%)$ \\
\hline \multirow{2}{*}{ Age } & Minimum & 25 years \\
\cline { 2 - 3 } & Maximum & 60 years \\
\hline
\end{tabular}

Table I. Sex and Age incidence in psoriasis.

\begin{tabular}{|c|c|c|}
\hline Type of psoriasis & No. of patients & Measuring scale \\
\hline Palmoplantar psoriasis & 32 & PASI \\
\hline Scalp psoriasis & 18 & PASI \\
\hline
\end{tabular}

Table II. Type of plaque psoriasis.

\begin{tabular}{l|c|c|}
\hline Palmoplantar psoriasis & Group-A & 16 \\
\cline { 2 - 3 } & Group-B & 16 \\
\hline \multirow{2}{*}{ Scalp psoriasis } & Group-A & 9 \\
\cline { 2 - 3 } & Group-B & 9 \\
\hline
\end{tabular}

\section{Drug and Dosage information}

Methotrexate is administered orally to the patients with plaque psoriasis involving $>10$ psoriasis area severity index (PASI). Methotrexate has some adverse effects like nausea, abdominal pain, fatigue, fever, and $7.5 \mathrm{mg}$ of MTX given once in a week for palmoplantar and scalp psoriasis. Calcipotriol is vitamin-D analogue, applied topically to the affected areas. It is available as ointment form as well as solution form. For treatment of palmoplantar psoriasis, calcipotriol $50 \mu \mathrm{g} / \mathrm{g}$ ointment is applied twice daily topically, whereas for treatment of scalp psoriasis, calcipotriol $50 \mu \mathrm{g} / \mathrm{ml}$ scalp solution is applied twice daily topically. Information about drugs and dosage information was mentioned in the following table (Tabl. IV).

\begin{tabular}{|c|c|l|l|l|}
\hline \multicolumn{1}{|c|}{ Drug } & $\begin{array}{c}\text { Dose and Route } \\
\text { of administration }\end{array}$ & Type of dosage form & \multicolumn{1}{|c|}{$\begin{array}{c}\text { Nature of } \\
\text { application }\end{array}$} & \multicolumn{1}{|c|}{ Plaque psoriasis } \\
\hline Methotrexate & $7.5 \mathrm{mg}$ Oral & Tablet & Once weekly & $\begin{array}{l}\text { Palmoplantar } \\
\text { Scalp psoriasis }\end{array}$ \\
\hline Calcipotriol & $50 \mu \mathrm{g} / \mathrm{g}$ Topical & Ointment & Twice daily & $\begin{array}{l}\text { Palmoplantar } \\
\text { Psoriasis }\end{array}$ \\
\cline { 2 - 5 } & $50 \mu \mathrm{g} / \mathrm{ml}$ Topical & Solution & Twice daily & Scalp psoriasis \\
\hline
\end{tabular}

Table IV. Drug and dosage information. 


\section{Experimental Design}

In this present study, 50 patients were subjected to all necessary investigations before and during administration of drugs. The investigations include PASI, Complete blood count and liver enzymes, creatinine, urea, alkaline phosphate. They are conducted every two weeks up to eight weeks. Here all group-A patients are treated with methotrexate, whereas all group-B patients were treated with combination of methotrexate and calcipotriol. The Complete information about PASI scores before drug administration are mentioned in the following table (Tabl. V).

\begin{tabular}{|c|l|l|l|l|}
\hline \multicolumn{2}{|c|}{} & Mean PASI score & \multicolumn{1}{c|}{ Drugs } \\
\hline \multirow{2}{*}{ Palmoplantar Psoriasis } & Group-A & 16 & 24.40 & MTX \\
\cline { 2 - 5 } & Group-B & 16 & 23.28 & MTX+ Calcipotriol \\
\hline \multirow{2}{*}{ Scalp psoriasis } & Group-A & 9 & 22.42 & MTX \\
\cline { 2 - 5 } & Group-B & 9 & 24.13 & MTX+Calcipotriol \\
\hline
\end{tabular}

\section{PASI scores}

The extent of psoriasis disease is measured by using PASI scales, PASI is used to measure palmoplantar and scalp psoriasis.

PASI scale is considered as gold standards for measurement of psoriasis, here total body is divided into four parts, and these are head, upper extremities, trunk, and lower extremities. The extent of erythema, thickness, and scales is measured for each organ and given scores range from 0-4. Area score is given for each organ based on the percentage of body organ affected with psoriasis and scores ranges from $0-6$. The scale mentioned is as below (Tabl. VI).

\begin{tabular}{|l|l|l|l|l|}
\hline & \multicolumn{1}{|c|}{ Head } & \multicolumn{1}{c|}{$\begin{array}{c}\text { Upper } \\
\text { Extremities }\end{array}$} & \multicolumn{1}{c|}{ Trunk } & Lower Extremities \\
\hline Redness & & & & \\
\hline Thickness & & & & \\
\hline Scale & & & & \\
\hline Sum & $\mathrm{A} 1=$ & $\mathrm{A} 2=$ & $\mathrm{A} 3=$ & $\mathrm{A} 4=$ \\
\hline Area score & $\mathrm{B} 1=$ & $\mathrm{B} 2=$ & $\mathrm{B} 3=$ & $\mathrm{B} 4=$ \\
\hline Multiply & $\mathrm{A} 1 \times \mathrm{B} 1 \times 0.1=\mathrm{C} 1$ & $\mathrm{~A} 2 \times \mathrm{B} 2 \times 0.2=\mathrm{C} 2$ & $\mathrm{~A} 3 \times \mathrm{B} 3 \times 0.3=\mathrm{C} 3$ & $\mathrm{~A} 4 \times \mathrm{B} 4 \times 0.4=\mathrm{C} 4$ \\
\hline Total & $\mathrm{C} 1=$ & $\mathrm{C} 2=$ & $\mathrm{C} 3=$ & $\mathrm{C} 4=$ \\
\hline
\end{tabular}

Table VI. PASI scores.

Redness, thickness, scale were given score range from 0-4.

Area score:

Score $1:<10 \%$

Score $2: 10-<30 \%$

Score 3: $30-<50 \%$

Score 4: $50-<70 \%$

Score 5: $70-<90 \%$

Score 6: $90-<100 \%$

PASI score: $\mathrm{C} 1+\mathrm{C} 2+\mathrm{C} 3+\mathrm{C} 4=$

\section{Inclusion and Exclusion criteria}

Inclusion criteria:

1. Patients with plaque psoriasis i.e. $>10$ PASI score

2. Patients must be suitable for systemic therapy and calcipotriol

3. Age of patients between 20 to 65 years
Exclusion criteria:

1. Patients with hypercalcemia.

2. Patients with previous history of liver diseases.

3. Patients with guttate, erythrodermic, inverse and pustular psoriasis.

4. Pregnancy and lactating women.

\section{Results}

Before starting the treatment each patient was evaluated with complete blood count, creatinine, urea, alkaline phosphatase, serum albumin, SGOT, SGPT and PASI score. During the treatment also these parameters were well monitored at 2, 4, 6, 8 , week's interval. The entire information was mentioned in the following Table VII. 


\begin{tabular}{|l|l|l|l|l|l|l|l|l|}
\hline & Groups & $\begin{array}{c}\text { Before drug } \\
\text { treatmen, Mean } \\
\text { values }\end{array}$ & Drug treatment & $\begin{array}{c}\text { At 2 } \\
\text { weeks }\end{array}$ & $\begin{array}{c}\text { At 4 } \\
\text { weeks }\end{array}$ & $\begin{array}{c}\text { At 6 } \\
\text { weeks }\end{array}$ & $\begin{array}{c}\text { At 8 } \\
\text { weeks }\end{array}$ & $\begin{array}{c}\text { \% reductionin } \\
\text { PASIScores }\end{array}$ \\
\hline $\begin{array}{l}\text { Palmo plantar } \\
\text { psoriasis }\end{array}$ & G-A & 24.40 & MTX & 23.93 & 20.54 & 17.36 & 13.86 & PASI 50 \\
\cline { 2 - 10 } & G-B & 23.28 & MTX+ Calcipotriol & 20.79 & 15.32 & 11.58 & 5.36 & PASI 75 \\
\hline Scalp psoriasis & G-A & 22.42 & MTX & 21.32 & 18.48 & 16.27 & 12.58 & PASI 50 \\
\cline { 2 - 10 } & G-B & 24.13 & MTX+Calcipotriol & 20.83 & 16.51 & 12.86 & 5.42 & PASI 75 \\
\end{tabular}

Table VII. Reduction in PASI score in palmoplantar and scalp psoriasis.

From the above table, we have observed that $75 \%$ reduction in PASI score is achieved with combination of methotrexate and calcipotriol, whereas $50 \%$ reduction in PASI score is achieved with methotrexate alone. $75 \%$ improvement in PASI score was considered as endpoint for clinical trials.

Methotrexate is considered as well known drug for treating psoriasis. Psoriasis is a complex disease, so combination therapy was preferred to treat psoriasis. Methotrexate may combine with UVB, retinoids, PUVA, Vitamin D analogues for improving its efficiency, limiting side effects, reducing doses.

In this study methotrexate was combined with Vitamin D analogue, Calcipotriol. Methotrexate alone and its combination with calcipotriol were given for 8 weeks for palmoplantar and scalp psoriasis. Calcipotriol $50 \mu \mathrm{g} / \mathrm{g}$ ointment is applied topically twice daily for palmoplantarpsoriasis, whereas $50 \mu \mathrm{g} /$ $\mathrm{ml}$ solution is applied topically twice daily for scalp psoriasis. $7.5 \mathrm{mg}$ of Methotrexate is administered once weekly alone to group A patients of palmoplantar, and scalp psoriasis, achieving PASI score between $50-75 \%$ is $8(32 \%)$ patients and $<50 \%$ is achieved in $13(52 \%)$ patients, $4(16 \%)$ patients were poor responders to methotrexate. Whereas combination of methotrexate and calcipotriol given for group B patients of palmoplantar and scalp psoriasis, achieving PASI scores, > $75 \%$ was achieved in $18(72 \%)$ patients, between $50-75 \%$ was achieved in 7 (28\%) patients (Tabl. VIII).

We observed that an increased efficiency in patients who used the combination (MTX + Calcipotriol) therapy than the methotrexate monotherapy. After treatment with methotrexate, investigations showed that no changes in complete blood count, SGOT, SGPT, alkaline phosphatase, creatinine, and serum albumin. In the present study we used low dose methotrexate, thereby side effects were minor, they were found in four patients, consisting of headache, nausea, skin itching and fever, whereas calcipotriol also produces some adverse effects in two patients, they are erythema, pruritus and burning.

\begin{tabular}{|c|c|c|}
\hline PASI scores & Group-AMTX alone & Group-BMTX+ Calcipotriol \\
\hline$>75$ & $0(0 \%)$ & $18(72 \%)$ \\
\hline $50-75$ & $8(32 \%)$ & $7(28 \%)$ \\
\hline$<50$ & $13(52 \%)$ & $0(0 \%)$ \\
\hline Table VIII. Number of patients within the PASI score range. \\
\end{tabular}

\section{Discussion}

Psoriasis is a complex disease; it is very difficult to treat with conventional therapy, in such case combination therapy is preferable to treat the disease (Fig. 1 and 2). During psoriasis skin cells grows too quickly and moves to the surface of the skin appears as dead cells. Psoriasis mainly occur due to cold weather, stress, alcohol drinking, smoking, hormones, cuts, tattoos, allergies, medication for high blood pressure, heart disease and psychiatric disorders.

In summer psoriasis undergoes remission and winter comes then relapse of psoriasis occur. Because sunlight having Ultra violet-A and Ultra violet-B rays. It may act as therapy for psoriasis. Some people suffering from psoriasis in summer more. Because sunlight acts as precipitating agent it may damage the skin.

M. Frincu et al. [10] Explained that, Combination of methotrexate and phototherapy has positive role as methotrexate doses are reduced, the administration time is reduced and the risk of occurrence of severe side effects, both blood and liver is low. A drawback of treatment with phototherapy was that the patient had to come almost every day to perform clinical cure with UV, with duration of at least one hour per day.

Treatment with methotrexate for four weeks cure psoriasis plaques, the same was explained by BL. Masuria et.al, [11] prior to the therapy, average involvement was $47.5 \%$ which after four weeks methotrexate therapy reduced to $8.3 \%$. A complete clearing of psoriasis occurred in $40 \%$ of patients after methotrexate therapy. The clinical response started as early as 1 sore throat week in most of the patients.

PASI score was considered as more reliable tool for measurement of extent of psoriasis plaques. According to NeerajaPuri et al, [12] PASI score remains the most accepted and widely used measure in clinical trials. Reduction in PASI score indicates decrease in severity of psoriasis. PASI 75 means $75 \%$ reduction in symptoms of psoriasis, whereas PASI 50 means $50 \%$ reduction in symptoms of psoriasis. PASI 75 considered as meaningful end point for clinical trials. 


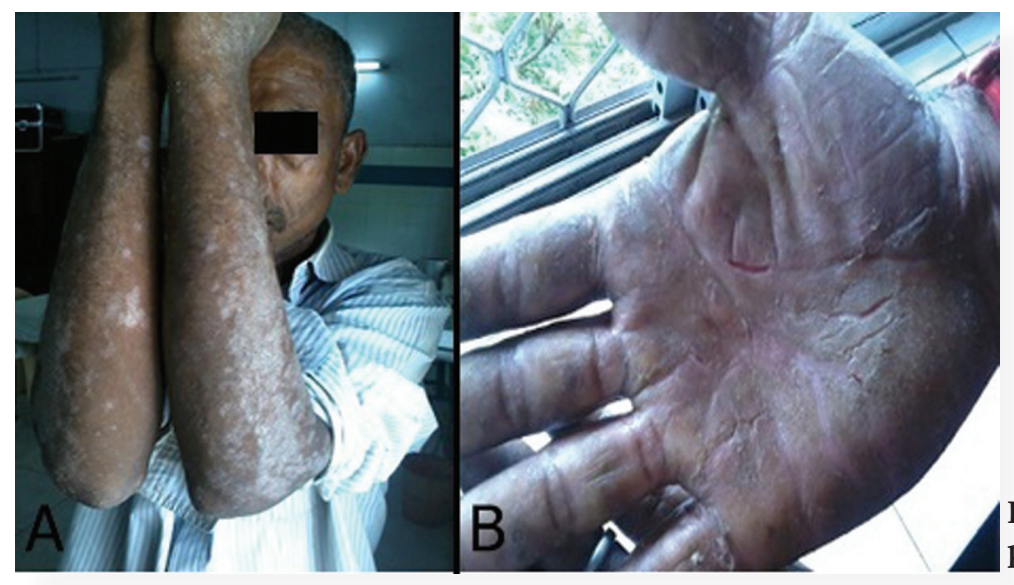

Figure $1 \mathrm{~A}$ and $\mathrm{B}$. The above picture shows the patient with psoriasis of palms of hands psoriasis.

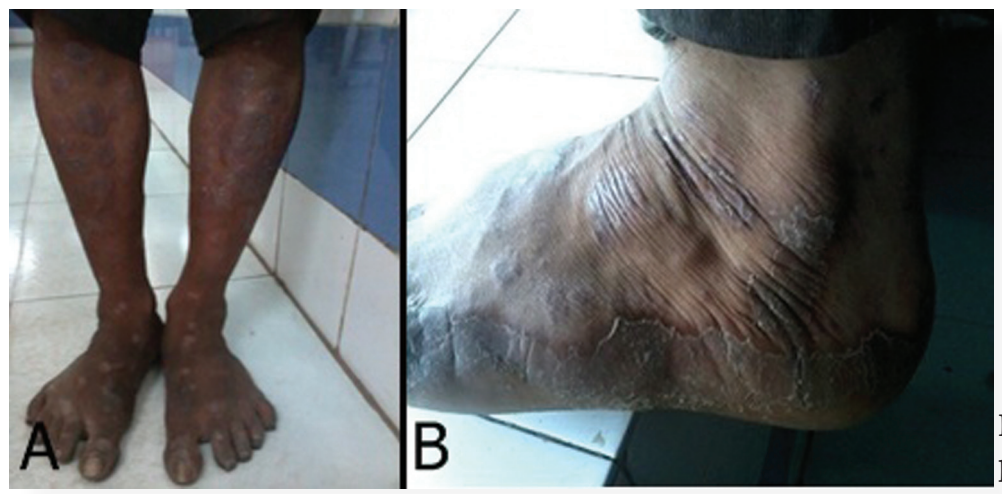

Figure2A and B. The above picture shows the patients with psoriasis of soles of feet.

Combination therapy is more effective than methotrexate alone; methotrexate was combined with various topical agents, oral agents and phototherapy. According to de Jong et al. [13], Menter MA et al [14]. Combination treatment minimizes the side effects associated with methotrexate and also reduces dose of methotrexate. This combination therapy also minimizes time of exposure of drug.

According to PVS Prasad et al [15] thirty five patients admitted with psoriasis were analyzed. Sixteen patients received $20 \%$ crude coal tar and 19 patients received $20 \%$ crude coal tar along with Methotrexare in a weekly oral schedule $(15 \mathrm{mg} / \mathrm{wk})$. After 4 weeks of therapy there was total clearance in $52.6 \%$ of the patients with combination therapy, whereas only $12.5 \%$ of the patients with conventional therapy achieved this. Chronic plaque psoriasis shows a high clearance rate if coal tar application is combined with oral methotrexate, than with the conventional coal tar alone.

According to Lin YK et al. [16] jerry Bajel et al. [17] topical vitamin $\mathrm{D}$ serves as a foundation, it increases safety and efficacy of all medications. There by topical vitamin D used in combination therapy with systemic agents and phototherapy. Vitamin D has immunomodulatory properties that decrease anti-microbial peptides in keratinocytes, which promotes inflammation process. It has anti-inflammatory and antiproliferative properties. Vitamin D decreases toxicity associated with these drugs used as monotherapy.

Methotrexate is known as gold standard drug for treatment of psoriasis, Leung WY et al. [18] and Talwar S et al. [19] stated that; methotrexate is one of the well-established drugs for the treatment of moderate to severe psoriasis. Careful selection of patients, pretreatment evaluation and post treatment monitoring of methotrexate is essential because of its serious adverse effects of methotrexate. Folate is usually added to reduce the adverse effects of methotrexate. Liver biopsy remains the gold standard to detect the methotrexate related hepatic fibrosis and it is recommended in patients who have received a cumulative dose of 1.0-1.5 g.

\section{Conclussion}

From the above study, we concluded that combination therapy is more effective in treating psoriasis compared to methotrexate as monotherapy. Combination therapy increases efficacy, reduce side effects and decreases chances of relapse. PASI 75 is achieved with combination therapy (Methotrexate + Calcipotriol) whereas PASI 50 is achieved with methotrexate monotherapy. PASI 75 was considered as end point for clinical trials. So combination therapy is more effective in treating psoriasis compared to methotrexate as monotherapy. Hence combination (Methotrexate + Calcipotriol) therapy plays a major role in treating palmoplantar and scalp psoriasis.

\section{REFERENCES}

1. Lever WF, Lever GS. Histopathology of skin, 7thedn. Philadelphia. JB Lippincott Company. 1990;156-64.

2. American Academy of Dermatology. Committee on guidelines of care for psoriasis. Jam Acad Dermatol. 1993;28:632-7.

3. Smith KC. Systemic therapy of psoriasis using methotrexate. Skin therapy Lett. 2000;6:1-2;5. 
4. Walsdorfer U, Chiristophers E, Schorder J-M. Methotrexate inhibits polymorphonuclear leucocyte chemotaxis in psoriasis. Br J Dermatol. 1983;108:451-6.

5. Roenigk HH Jr, Auerbach R, Maibach HI, Weinstein GD. Methotrxate in psoriasis: revised guidelines. J Am Acad Dermatol. 1988;19:145-50.

6. Kerkhof Van de PCM, Volden G, Gollinick H. Comparisons and combinations In: Mier PD, Kerkhof Van de PCM, eds. Textbook of psoriasis. Edinburgh: Churchill Livingstone, 1987;268-75.

7. Talwar S. Methotrexate PUVASOL combination in treatment of psoriasis. Indian J Dermatol Venereal Leprol. 1992;15-9.

8. Koo J. Systemic sequential therapy for psoriasis. NPF Psoriasis Forum. 1998;4:3.

9. Brunasso AM, Puntoni M, Delfino C, Massone C. Different response rates between palmoplantar involvement and diffuse plaque psoriasis in patients treated with infliximab. Eur J Dermatol. 2012;22:133-5.

10. Frincu M, Oanta A. Systemic therapy of moderate and severe psoriasis with methotrexate. Bulletin of Transilvania University of Brasov. Series 6: Medical sciences. 2012;5:2.

11. Masuria BL, Bansal NK, Sharma M, Singhi MK, Mittal A, Gupta LK. A clinic histopathological outcome of 4 weeks methotrexate pulse therapy in psoriasis. Indian J Dermatol Venereol Leprol. 1999;65:172-3.
12. Puri N, Mahajan BB, Sandhu SK. Clinical evaluation of different therapeutic modalities in psoriasis by PASI scores. Our Dermatol Online. 2013;4:16-22.

13. de Jong EM, Mørk NJ, Seijger MM, De La Brassine M, Lauharanta $\mathrm{J}$, Jansen CT, et al. The combination of calcipotriol and methotrexate compared with methotrexate and vehicle in psoriasis. Br J Dermatol. 2003;148:318-25.

14. Menter MA, See JA, Amend WJ, Ellis CN, Krueger GG, Lebwohl $\mathrm{M}$, et al. Proceedings of the psoriasis combinations and rotation therapy conference. J Acad Dermatol. 1996;34:315-21.

15. Prasad PVS, Felix J. Topical coal tar alone and in combination with oral methotrexate in management of psoriasis: A retrospective analysis. Indian J Dermatol Venereol Leprol. 1997;63:26-8.

16. Lin YK, Huang ZR, Zhuo RZ, Fang JY. Combination of calcipotriol and methotrexate in nanostructured lipid carriers for topical delivery. Int J Nanomedicine. 2010;5:117-28.

17. Bagel J. Combination Approaches Using Topical Vitamin D for psoriasis. Practical Dermatol. 2013:43-4.

18. Leung WY, Lau HK. The use of methotrexate in moderate to severe psoriasis. Hong Kong J Dermatol Venereol. 2009;17:13-9.

19. Talwar S, Tiwari VD, Lakhtakia R, Panvelkar V. Sequential clinic- histological study in psoriasis following methotrexate therapy. Indian J Venereol Leprol. 1995;61:284-7. 